\title{
Silencing of heat shock protein 27 increases the radiosensitivity of non-small cell lung carcinoma cells
}

\author{
LIPING XU ${ }^{1}$, XUEMEI LIN ${ }^{1}$, YIHUA ZHENG ${ }^{1}$ and HUA ZHOU ${ }^{2}$ \\ ${ }^{1}$ Department of Respiratory Disease, Jiangshan People's Hospital, Jiangshan, Zhejiang 324100; \\ ${ }^{2}$ Department of Respiratory Disease, The First Affiliated Hospital, Zhejiang University, Hangzhou, Zhejiang 310003, P.R. China
}

Received June 21, 2018; Accepted February 28, 2019

DOI: $10.3892 / \mathrm{mmr} .2019 .10263$

\begin{abstract}
Radiotherapy is a useful treatment for malignant tumors, including lung carcinoma; however, non-small cell lung carcinoma (NSCLC) is frequently insensitive to radiation. It has been reported that heat shock protein 27 (HSPB1) is a radioresistance-associated protein in nasopharyngeal carcinoma. In the present study, the role of HSPB1 in NSCLC cells induced by irradiation was investigated. The viability of cells was determined by a Cell Counting Kit- 8 assay. The apoptotic activity, cell cycle distribution and mitochondrial membrane potential (MMP) of cells were evaluated via flow cytometry. Reverse transcription-quantitative polymerase chain reaction and western blot analyses were employed to measure the expression of various genes and proteins. It was observed that knockdown of HSPB1 with small interfering RNA (si-HSPB1) markedly decreased the viability of A549 NSCLC cells and induced cell cycle arrest in the G2/M phase following exposure to $6 \mathrm{~Gy}$ irradiation. Furthermore, it was revealed that si-HSPB1 significantly downregulated cyclin B1 and cyclin G1 expression. Additionally, si-HSPB1 promoted apoptosis and depolarized the MMP of cells exposed to 6 Gy irradiation. The expression levels of B-cell lymphoma-2 (Bcl-2), mitochondrial cytochrome $c$ (cyto $c$ ) and pro-caspase- 8 were downregulated, whereas those of Bcl-2 associated X protein (Bax), cytosolic cyto $c$ and cleaved-caspase- 8 were upregulated. Collectively, silencing of HSPB1 increased the radiosensitivity of NSCLC cells by reducing cell viability, depolarizing the MMP, arresting the cell cycle in the $\mathrm{G} 2 / \mathrm{M}$ phase and promoting cell apoptosis. Therefore, HSPB1 may be a novel target for increasing radiosensitivity in the treatment of NSCLC.
\end{abstract}

Correspondence to: Dr Hua Zhou, Department of Respiratory Disease, The First Affiliated Hospital, Zhejiang University, 79 Qingchun Road, Hangzhou, Zhejiang 310003, P.R. China E-mail: huaz_zhouh@163.com

Key words: non-small cell lung carcinoma, heat shock protein 27, apoptosis, radiosensitivity

\section{Introduction}

Lung cancer (LC) is the most common malignant tumor globally, and the leading cause of cancer-associated mortality (1). The incidence of LC is second to prostate cancer in all malignant tumors in men and second only to breast cancer in women (1). LC is separated into two subtypes, small cell lung carcinoma (SCLC) and non-small cell lung carcinoma (NSCLC); NSCLC accounts for 70-85\% of total LC cases (2). Due to the absence of clinical symptoms during early stages, patients are frequently diagnosed with LC at advanced stages, therefore missing the ideal period for operation; the total surgical removal rate of NSCLC is only $\sim 25 \%$ (3). Radiotherapy is an effective treatment for malignant tumors, including LC (4), and is frequently combined with exeresis and chemotherapy in the treatment of LC (5).

Radiotherapy mainly involves treatment with ionizing radiation (IR), which, by direct or indirect actions, leads to the damage of cellular DNA and subsequently results in cell death $(6,7)$. The efficacy of radiotherapy depends on the sensitivity of tumor cells to radiation; tumors can become insensitive to radiation via the radioresistance of tumor cells or the protection of the tumor microenvironment, leading to the repair of damaged cells following IR $(7,8)$. NSCLC cells frequently develop varying degrees of radiation tolerance in the middle and later stages of radiotherapy, reducing its efficacy (9-11). Therefore, it is important to identify the underlying mechanisms to increase the radiosensitivity of NSCLC tumors.

Heat shock proteins (HSPs) are a family of important proteins with molecular chaperone functions in stress situations, including cold, infection, starvation, trauma, poisoning, and particularly in high temperature conditions; HSPs are involved in the folding, assembly and modification of proteins, and promote the tolerance of cells to stress $(12,13)$. HSP27 (also known as HSPB1) is an important member of the HSP family; HSP27 is involved in endoplasmic reticulum stress associated with protein misfolding, and is a regulator that contributes to the development of various types of tumors (14-16). HSP27 expression has been reported to be upregulated in various tumor cells, including NSCLC, hepatocellular carcinoma and prostate cancer cells (17-20). Additionally, it was observed that HSP27 was a radioresistance-associated protein in nasopharyngeal carcinoma (21); 
however, whether HSP27 is involved in radiosensitivity in NSCLC remains unclear.

In the present study, the HSP27 gene was silenced in human NSCLC A549 cells, and the effects of HSP27 silencing on the viability, apoptosis, mitochondrial membrane potential (MMP) and cell cycle of irradiated cells was determined. Additionally, the underlying molecular mechanisms were investigated.

\section{Materials and methods}

Cell culture and transfection. The human lung adenocarcinoma A549 cell line was purchased from American Type Culture Collection (Manassas, VA, USA). A549 cells were cultured in RPMI-1640 medium (Gibco; Thermo Fisher Scientific, Inc., Waltham, MA, USA) with $10 \%$ fetal bovine serum (Gibco; Thermo Fisher Scientific, Inc.), $100 \mathrm{U} / \mathrm{ml}$ penicillin and $100 \mu \mathrm{g} / \mathrm{ml}$ streptomycin (Beyotime Institute of Biotechnology, Shanghai, China) at $37^{\circ} \mathrm{C}$ with $5 \% \mathrm{CO}_{2}$. HSPB1-small interfering RNA (si-HSPB1) and siRNA negative control (NC) plasmids were obtained from Genewiz Inc. (Suzhou, China). The sequences of siRNA used in the current study were as follows: si-HSPB1 sense, 5'-UGAGACUGC CGCCAAGUAAUU-3' and antisense, 5'-UUACUUGGCGGC AGUCUCAUU-3'; si-NC sense, 5'-UAGCGACUAAACACA UCAAUU-3' and antisense, 5'-UUGAUGUGUUUAGUCGCU AUU-3'. A549 cells $\left(2 \times 10^{5}\right.$ cells/well) were transfected with si-HSPB1 $(50 \mathrm{nM})$ or si-NC $(50 \mathrm{nM})$ using Lipofectamine ${ }^{\circledR}$ 3000 (Thermo Fisher Scientific, Inc.). The mixture containing si-HSPB1 or si-NC plasmids $(15 \mu \mathrm{g})$, transfection reagents and A549 cell was incubated for $48 \mathrm{~h}$ at $37^{\circ} \mathrm{C}$. Following transfection for $48 \mathrm{~h}$, the cells were harvested and used for the subsequent experiments.

Cell Counting Kit-8 (CCK-8) assay. Following transfection, cells $\left(2 \times 10^{3}\right.$ cells/well, 96 -well plates) were subjected to irradiation (0 and $6 \mathrm{~Gy}$ ) for 24, 48, and $72 \mathrm{~h}$ using a PRIMUS ${ }^{\mathrm{TM}}$ Linear Accelerator (Siemens AG, Munich, Germany); the dose rate was $300 \mathrm{cGy} / \mathrm{min}$. Following treatment, CCK-8 reagent (MedChemExpress, Monmouth Junction, NJ, USA) was added to the cells, and cells were further incubated for $4 \mathrm{~h}$ at $37^{\circ} \mathrm{C}$. The absorbance was detected at $450 \mathrm{~nm}$ using a light absorption microplate reader (SpectraMax iD3; Molecular Devices, LLC, Sunnyvale, CA, USA).

Cell apoptosis assay. Following transfection and irradiation, cells were washed three times with PBS. Subsequently, cells were incubated with 1X Annexin Binding Buffer (BestBio, Shanghai, China) on ice for $3 \mathrm{~min}$ and then stained using Annexin V-fluorescein isothiocyanate and propidium iodide (PI) (BestBio) in darkness for $25 \mathrm{~min}$ at room temperature. Cell apoptosis was detected using a flow cytometer (FACSCalibur; BD Biosciences, San Jose, CA, USA) equipped with CellQuest software (version 3.3; BD Biosciences).

Mitochondrial membrane potential (MMP) assay. Cells were digested by $0.25 \%$ EDTA-trypsin (Thermo Fisher Scientific, Inc.) for $5 \mathrm{~min}$ at $37^{\circ} \mathrm{C}$ and stained with JC-1 solution (MedChemExpress) for $20 \mathrm{~min}$ at $37^{\circ} \mathrm{C}$. Then, cells were centrifuged at $800 \times \mathrm{g}$ for $2 \mathrm{~min}$ at $4^{\circ} \mathrm{C}$. Cells were collected and the MMP was investigated using a flow cytometer.

Cell cycle assay. The cell cycle was investigated using a DNA Content Quantitation Assay (Cell Cycle) kit (Beijing Solarbio Science \& Technology Co., Ltd., Beijing, China) according to the manufacturer's protocols. Briefly, following transfection and irradiation, cells were treated with $40 \mathrm{X}$ RNase A at $37^{\circ} \mathrm{C}$ for $20 \mathrm{~min}$. Then, cells were stained with PI solution at $4^{\circ} \mathrm{C}$ for $15 \mathrm{~min}$. Cell cycle distribution was analyzed using a flow cytometer.

Reverse transcription-quantitative polymerase chain reaction (RT-qPCR) assay. TRIzol ${ }^{\circledR}$ reagent (Thermo Fisher Scientific, Inc.) was used to isolate total RNA from cells. cDNA was synthesized using the ABScript II cDNA First Strand Synthesis kit (ABclonal Biotech Co., Ltd., Wuhan, China) according to the manufacturer's protocols. The $\mathrm{RT}$ reaction was performed at $42^{\circ} \mathrm{C}$ for $15 \mathrm{~min}$, followed by reverse transcriptase inactivation at $85^{\circ} \mathrm{C}$ for $15 \mathrm{sec}$. A SYBR Premix $\mathrm{Taq}^{\mathrm{TM}}$ II kit (Dalian Meilun Biotech Co., Ltd., Dalian, China) was used to amplify cDNA according to the manufacturer's protocols. The qPCR thermocycling conditions were: Preliminary denaturation at $95^{\circ} \mathrm{C}$ for $1 \mathrm{~min}$, followed by 30 cycles of denaturation at $94^{\circ} \mathrm{C}$ for $30 \mathrm{sec}$, annealing at $56^{\circ} \mathrm{C}$ for $40 \mathrm{sec}$ and extension at $72^{\circ} \mathrm{C}$ for $60 \mathrm{sec}$, followed by a final extension step at $72^{\circ} \mathrm{C}$ for $7 \mathrm{~min}$. The primers were presented in Table I. GAPDH was used as an internal reference. The $2^{-\Delta \Delta C q}$ method was (22) used to quantify relative gene expression.

Western blot assay. Total protein was isolated from cells using radioimmunoprecipitation assay buffer (Beijing Solarbio Science \& Technology Co., Ltd.). Cytosolic and mitochondrial proteins were extracted using a Cytoplasmic and Mitochondrial Protein Extraction kit (Sangon Biotech Co., Ltd., Shanghai, China). The Bradford method was employed to determine the concentration of protein extracts. Proteins (30 $\mu \mathrm{g} / \mathrm{sample}$ ) were separated via 10\% SDS-PAGE and then transferred to polyvinylidene difluoride membranes (EMD Millipore, Billerica, MA, USA). The membranes were blocked with $5 \%$ non-fat milk at $37^{\circ} \mathrm{C}$ for $1 \mathrm{~h}$, and then incubated at $4^{\circ} \mathrm{C}$ overnight with primary antibodies, including anti-HSPB1 (1:500; cat. no. ab216610; Abcam, Cambridge, UK), anti-cyclin B1 (1:600; cat. no. ab32053; Abcam), anti-cyclin G1 (1:800; cat. no. sc-8016; Santa Cruz Biotechnology, Inc., Dallas, TX, USA), anti-B-cell lymphoma-2 (Bcl-2; 1:1,000; cat. no. MA5-11757, Invitrogen; Thermo Fisher Scientific, Inc.), anti-Bcl-2 associated X protein (Bax; 1:1,000; cat. no. ab53154; Abcam), anti-pro-caspase-8 (1:700; cat. no. MAB704; R\&D Systems, Inc., Minneapolis, MN, USA), anti-cytochrome $c$ (cyto $c ; 1: 1,000$; cat. no. MAB897; R\&D Systems, Inc.), anti-cleaved caspase-8 (1:600; cat. no. 9429; Cell Signaling Technology, Inc., Danvers, MA, USA), anti-cyto $c$ oxidase IV (1:100; cat. no. ab33985; Abcam) and anti-GAPDH (1:800; cat. no. ab8245; Abcam). Membranes were then incubated at $37^{\circ} \mathrm{C}$ for $90 \mathrm{~min}$ with horseradish peroxidase-conjugated secondary antibodies [mouse anti-rabbit immunoglobulin $\mathrm{G}$ (IgG); 1:8,000; cat. no. 31464, Invitrogen; Thermo Fisher Scientific, Inc.; and goat anti-mouse IgG; 1:8,000; cat. no. ab97023, Abcam]. Protein bands were visualized using 
Table I. Primer sequences.

\begin{tabular}{llc}
\hline Primer & \multicolumn{1}{c}{ Sequence (5'-3') } & Product size (bp) \\
\hline HSPB1-Forward & AGTGGTCGCAGTGGTTAGG & 223 \\
HSPB1-Reverse & TCCTTGGTCTTGACCGTCAG \\
Cyclin B1-Forward & TTGTGTGCCCAAGAAGATGC \\
Cyclin B1-Reverse & GAAGTGCAAAGGTAGAGGCC & 205 \\
Cyclin G1-Forward & CCTTCTGTGTTGGCATTGTCT \\
Cyclin G1-Reverse & GTACGCCCAGAAACAATCCA & 221 \\
Bcl-2-Forward & TTCTTTGAGTTCGGTGGGGT \\
Bcl-2-Reverse & CTTCAGAGACAGCCAGGAGA & 209 \\
Bax-Forward & CATCATGGGCTGGACATTGG \\
Bax-Reverse & CCTCAGCCCATCTTCTTCCA & 226 \\
GAPDH-Forward & CCATCTTCCAGGAGCGAGAT & 222 \\
GAPDH-Reverse & TGCTGATGATCTTGAGGCTG &
\end{tabular}

Bcl-2, B-cell lymphoma-2; Bax, Bcl-2-associated X protein; HSPB1, heat shock protein 27.

enhanced chemiluminescence detection reagent (Thermo Fisher Scientific, Inc.) and the densitometry was performed using the Bio-Rad ChemiDoc system with Image Lab software version 6.0 (Bio-Rad Laboratories, Inc., Hercules, CA, USA).

Statistical analysis. All data were presented as the mean \pm standard deviation. All experiments were performed in triplicate. Data were analyzed using GraphPad Prism 6.0 (GraphPad Software, Inc., La Jolla, CA, USA). Differences were analyzed using Student's t-tests or one-way analyses of variance followed by Tukey's post hoc test. $\mathrm{P}<0.05$ was considered to indicate a statistically significant difference.

\section{Results}

Silencing of HSPB1 promotes the radiosensitivity of NSCLC cells by reducing viability, arresting the cell cycle, depolarizing the MMP and promoting apoptosis. RT-qPCR and western blot analyses demonstrated that the expression levels of HSPB1 in A549 cells were significantly downregulated following transfection with si-HSPB1 compared with the NC (Fig. 1), with a knockdown efficiency of $>40 \%$. A CCK-8 assay revealed that irradiation with 6 Gy significantly decreased the viability of cells at 48 and $72 \mathrm{~h}$ compared with 0 Gy irradiation (Fig. 2A). Furthermore, irradiation with 6 Gy significantly increased the apoptotic rate by $>10 \%$ compared with no irradiation ( $0 \mathrm{~Gy})$, whereas the number of red fluorescent cells decreased by $\sim 30 \%$ following irradiation (Fig. 2B-E). In Fig. 2B the upper right quadrant is the advanced apoptotic cells, and the lower right quadrant was the early apoptotic cells. The rate of apoptotic cells is the sum of the rate of early and advanced apoptotic cells. Furthermore, arrest of the cell cycle in the G2/M phase was markedly promoted by irradiation when compared with the corresponding 0 Gy group (Fig. 3). In si-HSPB1 group, the percentage of cells in $\mathrm{S}$ phase was notably decreased, whereas the percentage of cells in $\mathrm{G} 2 / \mathrm{M}$ phase was markedly increased following irradiation with 6 Gy compared with the NC group. Furthermore, si-HSPB1 notably enhanced the effects of radiation on the viability, apoptosis, cell cycle distribution and MMP of NSCLC cells (Figs. 2 and 3).

Silencing of HSPBI increases the radiosensitivity of NSCLC cells by altering the expression of cell cycle-and apoptosis-associated genes. To investigate the mechanisms underlying the effects of irradiation and si-HSPB1 on the cell cycle, the expression of associated genes and proteins was determined by RT-qPCR and western blot assays. It was revealed that irradiation of A549 cells with 6 Gy significantly downregulated the mRNA levels of cyclin B1 and cyclin G1 compared with the corresponding 0 Gy control group (Fig. 4A and B). Additionally, transfection of cells with si-HSPB1 significantly decreased the levels of cyclin B1 and cyclin G1 mRNA compared with the NC, and promoted the effects of irradiation on expression. The expression of apoptosis-associated genes was also investigated. Irradiation significantly increased the expression of Bax and decreased that of Bcl-2 compared with $0 \mathrm{~Gy}$, and transfection with si-HSPB1 exhibited similar effects on expression when compared with the NC group (Fig. 4C and D). Additionally, transfection of irradiated cells with si-HSPB1 further promoted the effects of irradiation. Furthermore, western blotting revealed that 6 Gy irradiation and si-HSPB1 similarly affected the expression of cyclin B1, cyclin G1, Bax and Bcl-2 at the protein level (Fig. 5). It was also demonstrated that irradiation and si-HSPB1 significantly decreased the expression of pro-caspase- 8 and increased that of cleaved caspase- 8 compared with their respective controls.

Silencing of HSPB1 and irradiation increase the expression of cytosolic cyto $c$ and reduce the expression of mitochondrial cyto $c$. Increased mitochondrial membrane permeability is associated with the opening of the mitochondrial permeability transition pore (23). To investigate the molecular mechanisms underlying the effects of HSPB1 silencing and irradiation on the MMP, the expression of cyto $c$ was determined by western blotting. It was revealed that $6 \mathrm{~Gy}$ irradiation significantly decreased the mitochondrial levels of cyto $c$ and increased 

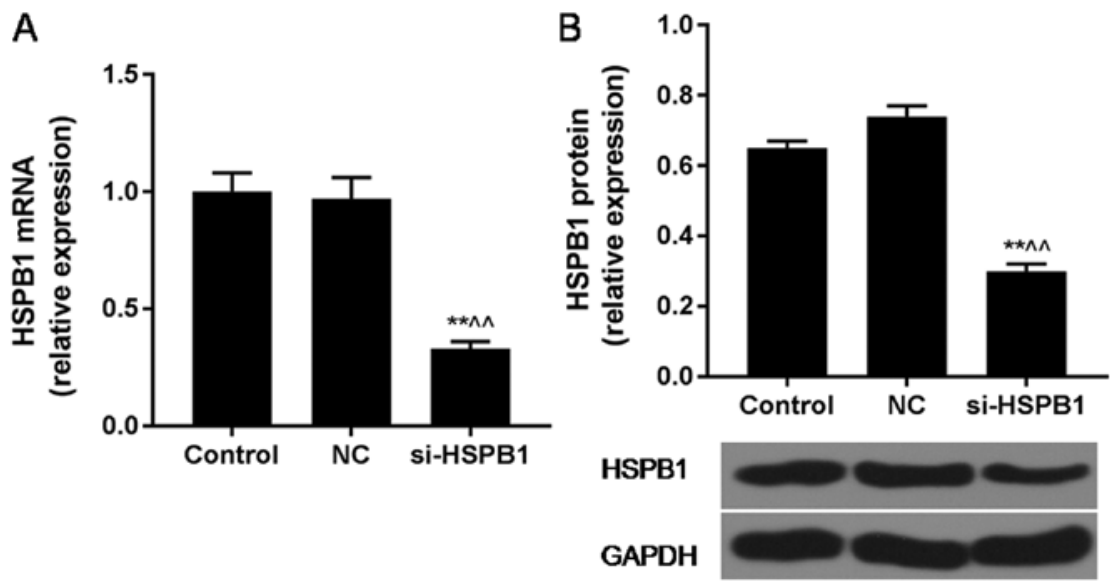

Figure 1. Transfection efficiency of HSPB1 in non-small cell lung carcinoma cells. (A) Expression of HSPB1 mRNA in A549 cells following transfection with si-HSPB1 and NC plasmids, as determined by reverse transcription-quantitative polymerase chain reaction analysis. (B) Expression of HSPB1 protein in transfected A549 cells, as determined by western blot analysis. Data are presented as the mean \pm standard deviation. ${ }^{* *} \mathrm{P}<0.01$ vs. control; ${ }^{\wedge} \mathrm{P}<0.01 \mathrm{vs}$. NC. HSPB1, heat shock protein 27; NC, negative control; si-HSPB1, small interfering RNA specific for HSPB1.

A
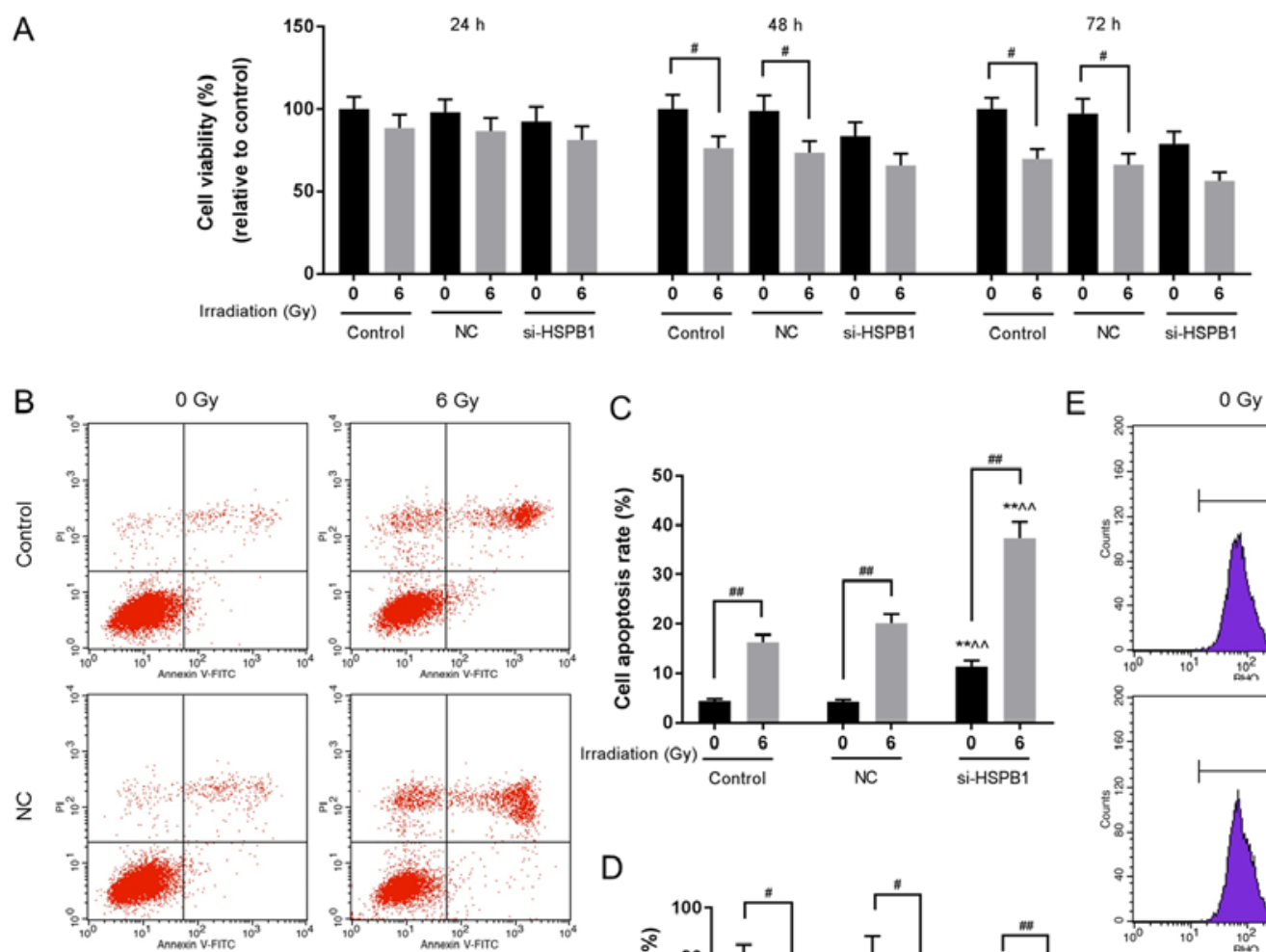

C

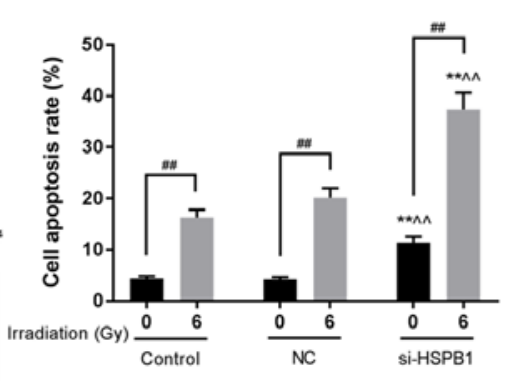

$\mathrm{E}$
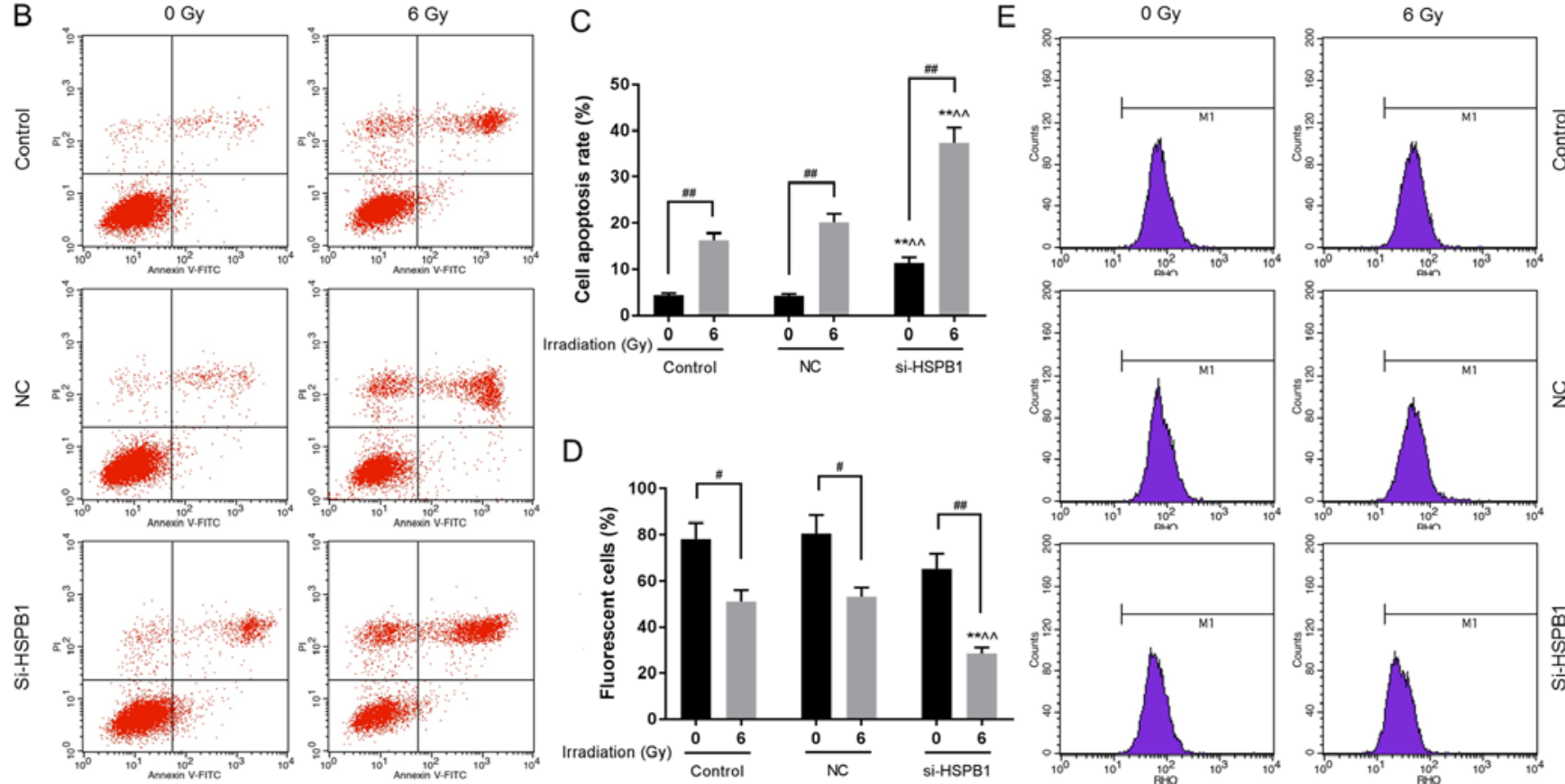

Figure 2. Silencing HSPB1 increases the radiosensitivity of non-small cell lung carcinoma cells by decreasing cell viability, promoting apoptosis and depolarizing the MMP. (A) The viability of A549 cells following irradiation with 0 or 6 Gy, and transfection with control, NC or si-HSPB1, as determined by a Cell Counting Kit-8 assay. (B and C) Apoptosis and (D and E) MMP of A549 cells following irradiation and transfection, as determined by flow cytometry. Data are presented as the mean \pm standard deviation. ${ }^{\#} \mathrm{P}<0.05$ and ${ }^{\# \#} \mathrm{P}<0.01$, as indicated; ${ }^{* *} \mathrm{P}<0.01$ vs. 0 Gy $+\mathrm{NC} ;{ }^{\wedge} \mathrm{P}<0.01$ vs. 6 Gy $+\mathrm{NC}$. FITC, fluorescein isothiocyanate; HSPB1, heat shock protein 27; MMP, mitochondrial membrane potential; NC, negative control; PI, propidium iodide; si-HSPB1, small interfering RNA specific for HSPB1.

those of cytosolic cyto $c$ compared with 0 Gy; si-HSPB1 also had similar significant effects on cyto $c$ expression (Fig. 6).
Furthermore, the effects of irradiation were promoted by transfection with si-HSPB1 (Fig. 6). 

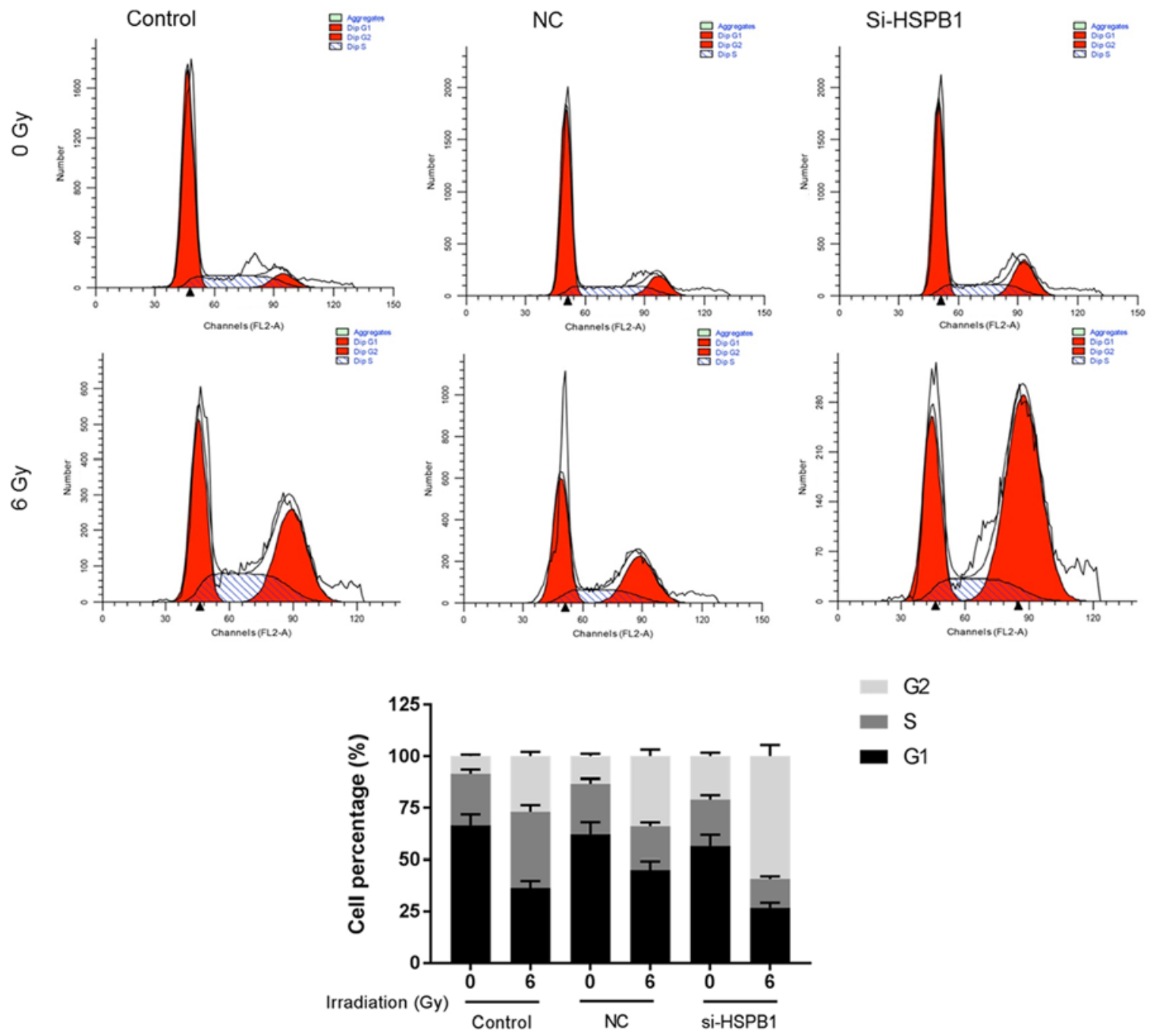

Figure 3. Silencing of HSPB1 increases the radiosensitivity of non-small cell lung carcinoma cells by inducing cell cycle arrest. The cell cycle distribution of A549 cells following irradiation with 0 or $6 \mathrm{~Gy}$, and transfection with control, NC or si-HSPB1, as determined by flow cytometry. Data are presented as the mean \pm standard deviation. HSPB1, heat shock protein 27; NC, negative control; si-HSPB1, small interfering RNA specific for HSPB1.

\section{Discussion}

At present, radiation therapy is an effective treatment of LC in clinical settings $(4,5)$; however, radiosensitivity and radioresistance serve important roles in the therapeutic effects of radiotherapy (24-26). Compared with SCLC, NSCLC is frequently insensitive to radiation, reducing the efficacy of radiotherapy as a treatment of NSCLC (27). Therefore, the aims of the present study were to investigate the mechanisms underlying the radioresistance of NSCLC cells and identify novel targets for improving radiosensitivity. It has been reported that HSPB1 was upregulated in NSCLC (20). In addition, it was demonstrated that knockdown of HSPB1 increased the radiosensitivity of nasopharyngeal carcinoma and head-neck cancer cells $(21,28)$. Therefore, it was hypothesized that silencing HSPB1 may increase the radiosensitivity of NSCLC cells.

Transfection with si-HSPB1 markedly decreased the viability of A549 cells following irradiation. One of the main effects of radiation on tumor cells is the induction of apoptosis (29). Additionally, depolarization of the MMP is associated with apoptosis (30). Thus, the apoptosis and
MMP of A549 cells following irradiation and silencing of HSPB1 was investigated. It was demonstrated that irradiation promoted the apoptosis and depolarized the MMP of NSCLC cells, with si-HSPB1 further enhancing the effects of irradiation. These findings indicated that downregulation of HSPB1 increased the radiosensitivity of NSCLC via the induction of apoptosis. The molecular mechanisms underlying radiosensitization include alterations in the tumor microenvironment, fixation of free radicals, cell cycle arrest, inhibition of DNA damage repair and the promotion of apoptosis (31-33). Cell cycle distribution is an important factor influencing radiosensitivity. The sensitivity of tumor cells to irradiation depends on their cell cycle phase (34); cells in the G2/M phase are more sensitive to radiation than those in other phases (35-37). It has been reported that drugs and gene manipulations increased the radiosensitivity of NSCLC cells by promoting G2/M phase cell cycle arrest (38-41). Consistent with these previous studies, the present study demonstrated that HSPB1 silencing markedly increased irradiation-induced cell cycle arrest in the G2/M phase.

As important regulators of the cell cycle, the roles of cyclins in the development and progression of tumors have 

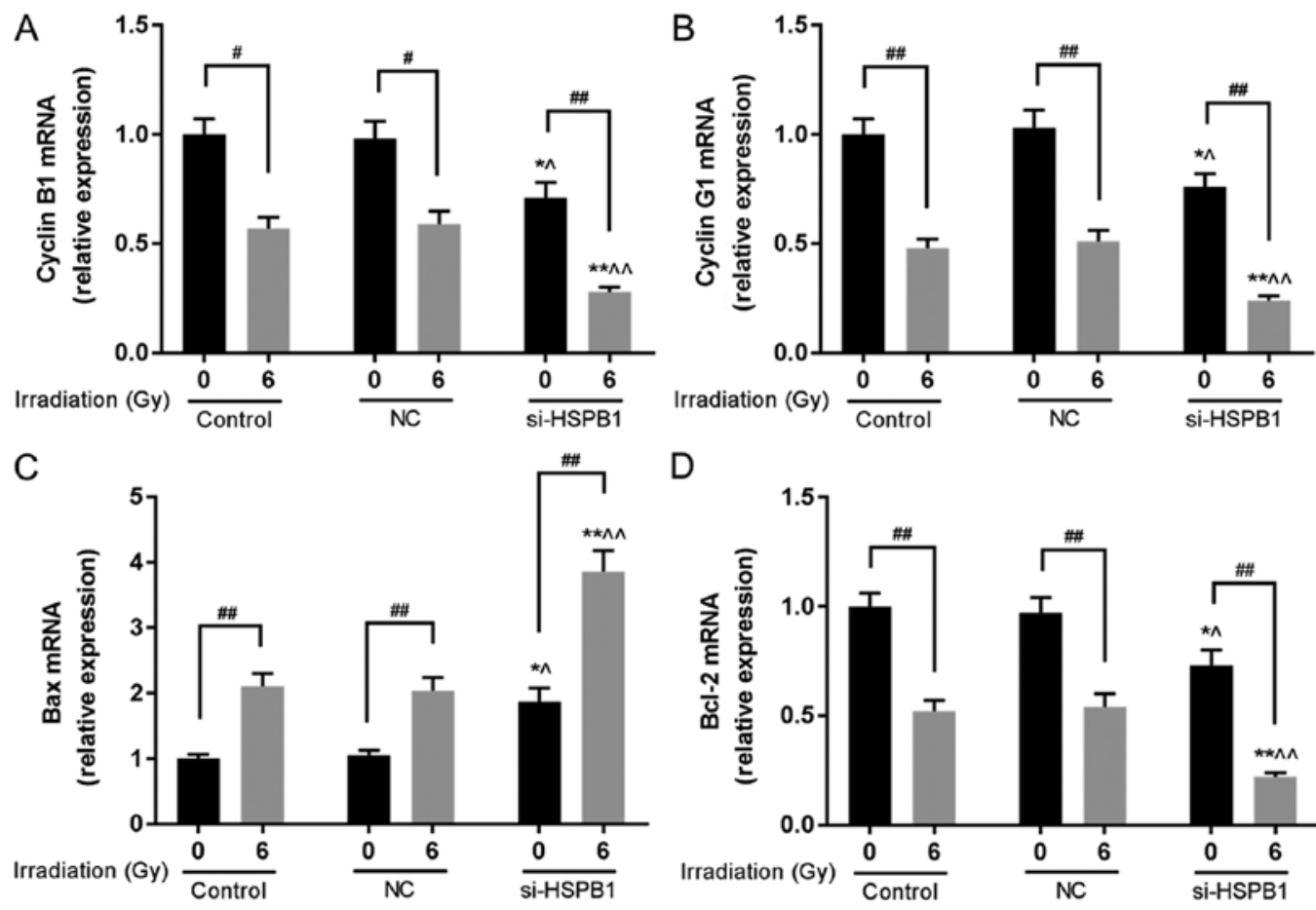

Figure 4. Silencing of HSPB1 increases the radiosensitivity of non-small cell lung carcinoma cells by regulating the expression of cell cycle- and apoptosis-associated genes. mRNA expression of (A) cyclin B1, (B) cyclin G1, (C) Bax and (D) Bcl-2 in A549 cells following irradiation with 0 or 6 Gy, and transfection with control, NC or si-HSPB1, as determined by reverse transcription-quantitative polymerase chain reaction. Data are presented as the mean \pm standard deviation. ${ }^{\#} \mathrm{P}<0.05$ and ${ }^{\# \#} \mathrm{P}<0.01$, as indicated; ${ }^{*} \mathrm{P}<0.05$ and ${ }^{* *} \mathrm{P}<0.01$ vs. 0 Gy $+\mathrm{NC} ;{ }^{\wedge} \mathrm{P}<0.05$ and ${ }^{\wedge \wedge} \mathrm{P}<0.01$ vs. 6 Gy $+\mathrm{NC}$. Bcl-2, B-cell lymphoma-2; Bax, Bcl-2-associated $\mathrm{X}$ protein; HSPB1, heat shock protein 27; NC, negative control; si-HSPB1, small interfering RNA specific for HSPB1.
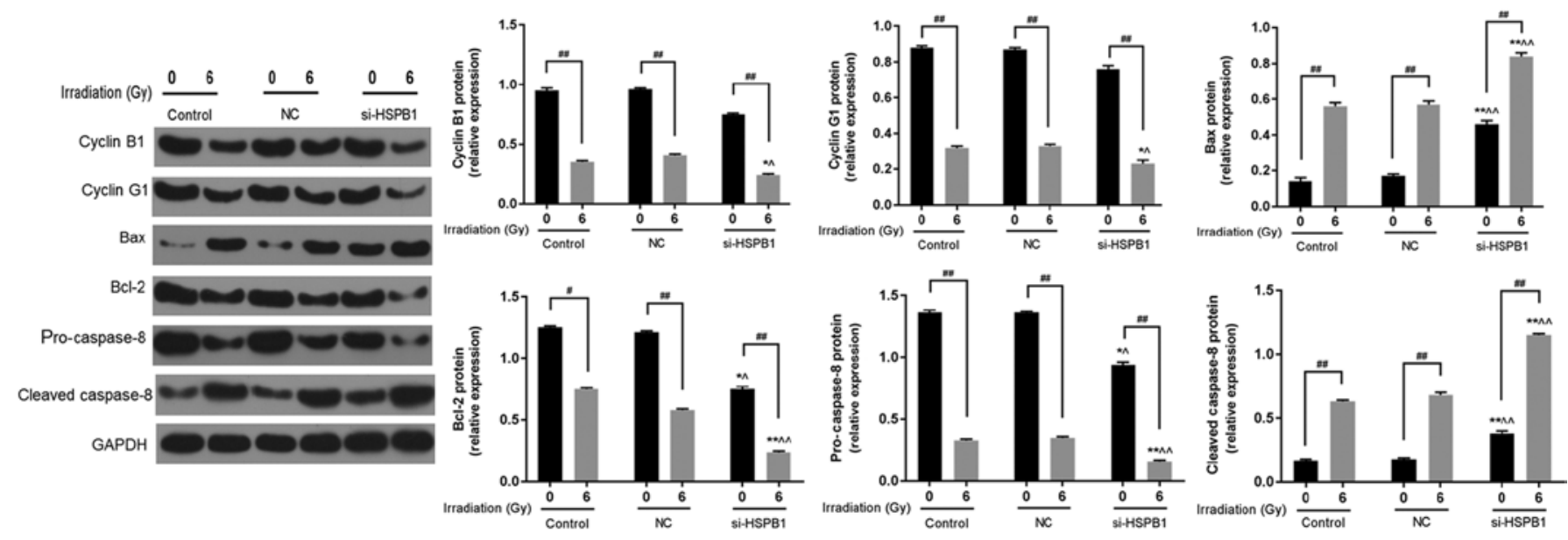

Figure 5. Silencing of HSPB1 increases the radiosensitivity of non-small cell lung carcinoma cells by regulating the expression of cell cycle- and apoptosis-associated proteins. Representative western blot and protein expression of cyclin B1, cyclin G1, Bax, Bcl-2, pro-caspase-3 and cleaved caspase-3 in A549 cells following irradiation with 0 or $6 \mathrm{~Gy}$, and transfection with control, $\mathrm{NC}$ or si-HSPB1. Data are presented as the mean \pm standard deviation. "P<0.05 and ${ }^{\# \#} \mathrm{P}<0.01$, as indicated; ${ }^{*} \mathrm{P}<0.05$ and ${ }^{* *} \mathrm{P}<0.01$ vs. 0 Gy $+\mathrm{NC} ;{ }^{\wedge} \mathrm{P}<0.05$ and ${ }^{\wedge} \mathrm{P}<0.01$ vs. $6 \mathrm{~Gy}+\mathrm{NC}$. Bcl-2, B-cell lymphoma-2; Bax, Bcl-2-associated $\mathrm{X}$ protein; HSPB1, heat shock protein 27; NC, negative control; si-HSPB1, small interfering RNA specific for HSPB1.

been investigated; the abnormal expression of cyclins is a common mechanism underlying the dysregulation of cell cycle in malignant tumors (42-44). Cyclins are involved in cell cycle arrest $(45,46)$. Cyclin B1 and cyclin G1 regulate G2/M phase transition (47). In the present study, cyclin B1 and cyclin G1 levels were detected by RT-qPCR and western blot analyses in A549 cells transfected with si-HSPB1 and exposed to radiation. It was demonstrated that the combination of si-HSPB1 and irradiation significantly decreased the expression levels of cyclin B1 and cyclin G1, suggesting that silencing HSPB1 increases the radiosensitivity of HSPB1 cells by arresting the cell cycle in the G2/M phase via the downregulation of cyclins.

Apoptosis is associated with radiosensitivity; increased apoptosis indicates elevated radiosensitivity (48-50). Numerous molecules and pathways are involved in apoptotic processes, including the mitochondria, which serve key roles (51-53). For example, the voltage-dependent anion channel 1 (VDAC1) plays a key role in mitochondrial mediated apoptosis, VDAC1 

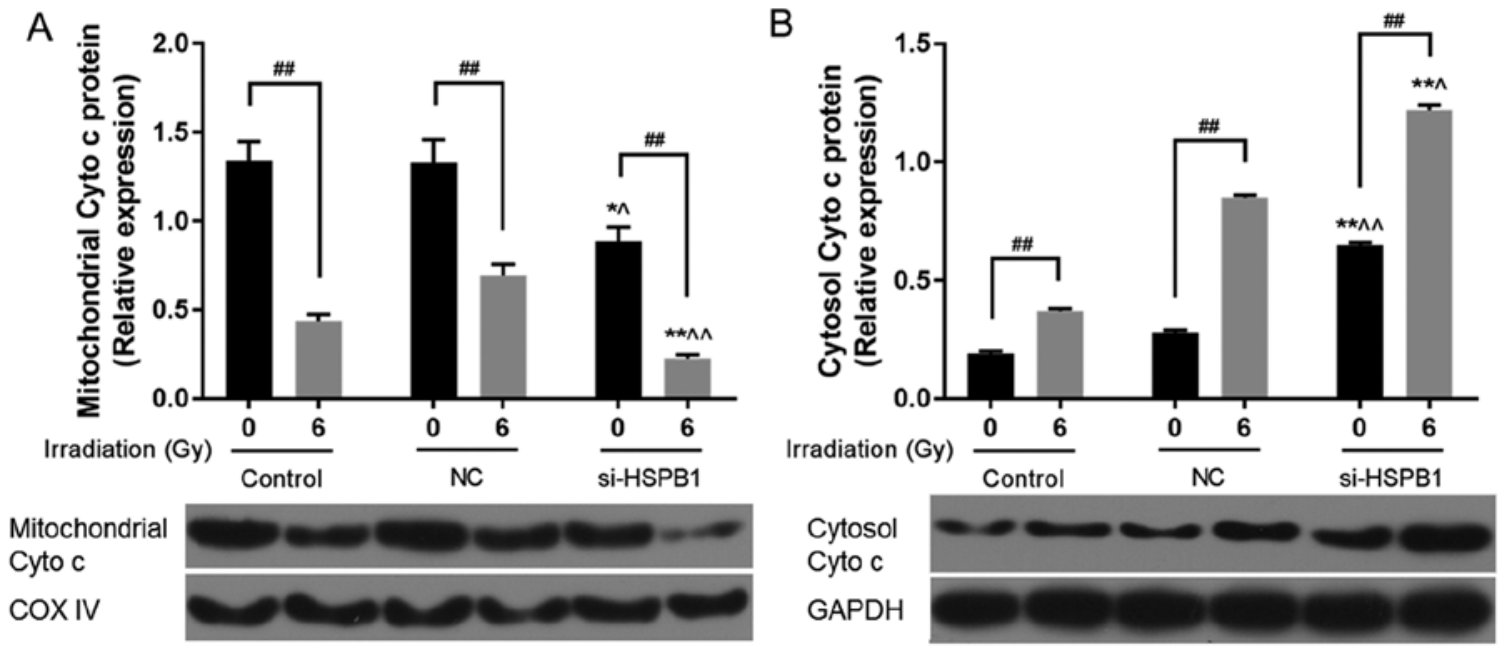

Figure 6. Silencing of HSPB1 increases the radiosensitivity of non-small cell lung carcinoma cells by regulating the expression of cytosolic and mitochondrial cyto $c$. (A and B) Representative western blots and the protein expression of mitochondrial cyto $c$ and cytosolic cyto $c$ in A549 cells following irradiation with 0 or $6 \mathrm{~Gy}$, and transfection with control, NC or si-HSPB1. ${ }^{\# \#} \mathrm{P}<0.01$, as indicated; ${ }^{*} \mathrm{P}<0.05$ and ${ }^{* *} \mathrm{P}<0.01$ vs. 0 Gy $+\mathrm{NC} ;{ }^{\wedge} \mathrm{P}<0.05$ and ${ }^{\wedge \wedge} \mathrm{P}<0.01$ vs. $6 \mathrm{~Gy}+\mathrm{NC}$. cyto $c$, cytochrome $c$; COX IV, cyto $c$ oxidase IV; HSPB1, heat shock protein 27; NC, negative control; si-HSPB1, small interfering RNA specific for HSPB1.

oligomerization leads to the formation of a large pore that allows the release of pro-apoptotic proteins to cytosol, thereby activating apoptosis (51); Mitogen-activated protein kinases/extracellular signal-regulated kinase pathway has been reported to be associated with cell differentiation and apoptosis (54). Depolarization of the MMP is an early event in apoptotic cascades, leading to a series of biochemical alterations in the mitochondrial membrane that induce proapoptotic pathways $(55,56)$. In the present study, it was observed that downregulation of HSPB1 increased apoptosis and altered the MMP in A549 cells following irradiation.

Apoptosis pathways can be divided into extracellular and intracellular apoptotic pathways $(57,58)$. The external pathway is mainly regulated by caspase- 8 , which is activated by apoptotic receptors on the surface of the cell membrane $(59,60)$. The internal pathway involves $\mathrm{Bcl}-2$ and Bax, which regulate the permeability of the outer membrane of mitochondria (61). Bcl-2 exhibits antiapoptotic effects and prevents the release of cyto $c$ from mitochondria into the cytoplasm (62). Activation of the proapoptotic protein Bax accelerates cell death (58). Therefore, the expression of Bcl-2, Bax, cyto $c$ and caspase- 8 was investigated in A549 cells subjected to si-HSPB1 transfection and irradiation. It was demonstrated that si-HSPB1 upregulated the levels of Bax, cytosol cyto $c$ and cleaved caspase-8, and downregulated those of Bcl-2, mitochondrial cyto $c$ and pro-caspase- 8 in cells exposed to irradiation. These findings indicated that HSPB1 silencing promoted the apoptosis of NSCLC cells following radiation treatment.

There are certain points to consider for future experiments. NSCLC accounts for the majority of lung cancers (63); however, the present study did not investigate the effects of HSPB1 silencing on SCLC cells, which should be determined in future studies. Additionally, a previous study reported that HSPs did not regulate the radioresistance of NSCLC cells, with no effect following the downregulation of HSP72 or heat shock treatment (64). The reasons for the discrepancy between the absence of a reported effect of heat shock treatment on
NSCLC cell radiosensitivity in the previous study and the increase in radiosensitivity following silencing of HSPB1 in the present study require further investigation.

In conclusion, the results of the present study demonstrated that silencing HSPB1 increased the radiosensitivity of NSCLC cells via reductions in cell viability, depolarization of the MMP, cell cycle arrest in the G2/M phase and the promotion of apoptosis. Therefore, HSPB1 may be a potential target for the treatment of radiation-insensitive NSCLC.

\section{Acknowledgements}

Not applicable.

\section{Funding}

No funding was received.

\section{Availability of data and materials}

The datasets used and/or analyzed during the current study are available from the corresponding author on reasonable request.

\section{Authors' contributions}

LX made substantial contributions to the conception and design of the present study; XL, YZ and HZ performed data acquisition, analysis and interpretation; LX drafted the article or critically revised it for important intellectual content; all authors agreed to be accountable for all aspects of the work and ensuring that questions related to the accuracy or integrity of the work were appropriately investigated and resolved; all authors approved the final published version.

\section{Ethics approval and consent to participate}

Not applicable. 


\section{Patient consent for publication}

Not applicable.

\section{Competing interests}

The authors declare that they have no competing interests.

\section{References}

1. Siegel R, Ma J, Zou Z and Jemal A: Cancer statistics, 2014. CA Cancer J Clin 64: 9-29, 2014.

2. Jemal A, Siegel R, Xu J and Ward E: Cancer statistics, 2010. CA Cancer J Clin 60: 277-300, 2010.

3. Ellis PM and Vandermeer R: Delays in the diagnosis of lung cancer. J Thorac Dis 3: 183-188, 2011.

4. Benveniste MF, Welsh J, Godoy MC, Betancourt SL, Mawlawi OR and Munden RF: New era of radiotherapy: An update in radiation-induced lung disease. Clin Radiol 68: e275-e290, 2013.

5. Fox W and Scadding JG: Medical research council comparative trial of surgery and radiotherapy for primary treatment of small-celled or oat-celled carcinoma of bronchus. Ten-year follow-up. Lancet 2: 63-65, 1973.

6. Changizi V, Bahrami M, Esfahani M and Shetab-Boushehri SV: Prevention of $\gamma$-radiation-induced DNA damage in human lymphocytes using a serine-magnesium sulfate mixture. Sultan Qaboos Univ Med J 17: e162-e167, 2017.

7. Triggiani L, Colosini A, Buglione M, Pasinetti N, Orizio F, Bardoscia L, Borghetti P, Maddalo M, Spiazzi L, Magrini SM and Bresciani R: Exploring the role of enzalutamide in combination with radiation therapy: An in vitro study. Anticancer Res 38 3487-3492, 2018

8. Murad H, Alghamian Y, Aljapawe A and Madania A: Effects of ionizing radiation on the viability and proliferative behavior of the human glioblastoma T98G cell line. BMC Res Notes 11: $330,2018$.

9. Kased N, Erasmus JJ, Komaki R and Cox JD: Prognostic value of posttreatment [18F] fluorodeoxyglucose uptake of primary non-small cell lung carcinoma treated with radiation therapy with or without chemotherapy: A brief review. J Thorac Oncol 3 : 534-538, 2008

10. Nagata Y and Kimura T: Stereotactic body radiotherapy (SBRT) for stage I lung cancer. Jpn J Clin Oncol 48: 405-409, 2018.

11. Skrzypski M and Jassem J: Consolidation systemic treatment after radiochemotherapy for unresectable stage III non-small cell lung cancer. Cancer Treat Rev 66: 114-121, 2018

12. Deniset JF and Pierce GN: Heat shock proteins: Mediators of atherosclerotic development. Curr Drug Targets 16: 816-826, 2015.

13. Zhang L, Fok JH and Davies FE: Heat shock proteins in multiple myeloma. Oncotarget 5: 1132-1148, 2014.

14. Albany C and Hahn NM: Heat shock and other apoptosis-related proteins as therapeutic targets in prostate cancer. Asian J Androl 16: 359-363, 2014.

15. Choi B, Choi SK, Park YN, Kwak SY, Lee HJ, Kwon Y, Na Y and Lee YS: Sensitization of lung cancer cells by altered dimerization of HSP27. Oncotarget 8: 105372-105382, 2017.

16. McConnell JR and McAlpine SR: Heat shock proteins 27, 40, and 70 as combinational and dual therapeutic cancer targets. Bioorg Med Chem Lett 23: 1923-1928, 2013.

17. Huang Z, Yang C, Sun S, Nan Y, Lang Z, Wang X, Zhao J and Liu Y: Heat shock protein 27, a novel regulator of transforming growth factor $\beta$ induced resistance to cisplatin in A549 cell. Pharmacology 100: 283-291, 2017.

18. Stope MB, Weiss M, Preuss M, Streitbörger A, Ritter CA Zimmermann U, Walther R and Burchardt M: Immediate and transient phosphorylation of the heat shock protein 27 initiates chemoresistance in prostate cancer cells. Oncol Rep 32: 2380-2386, 2014.

19. Zhang Y, Tao X, Jin G, Jin H, Wang N, Hu F, Luo Q, Shu H, Zhao $\mathrm{F}$, Yao $\mathrm{M}$, et al: A targetable molecular chaperone Hsp27 confers aggressiveness in hepatocellular carcinoma. Theranostics 6: 558-570, 2016

20. Zhao GY, Ding JY, Lu CL, Lin ZW and Guo J: The overexpression of 14-3-3 and Hsp27 promotes non-small cell lung cancer progression. Cancer 120: 652-663, 2014.
21. Zhang B, Qu JQ, Xiao L, Yi H, Zhang PF, Li MY, Hu R, Wan XX, $\mathrm{He} \mathrm{QY}, \mathrm{Li} \mathrm{JH}$, et al: Identification of heat shock protein 27 as a radioresistance-related protein in nasopharyngeal carcinoma cells. J Cancer Res Clin Oncol 138: 2117-2125, 2012.

22. Livak KJ and Schmittgen TD: Analysis of relative gene expression data using real-time quantitative PCR and the 2(-Delta Delta C(T)) method. Methods 25: 402-408, 2001.

23. Bernardi P, Rasola A, Forte M and Lippe G: The mitochondrial permeability transition pore: Channel formation by F-ATP synthase, integration in signal transduction, and role in pathophysiology. Physiol Rev 95: 1111-1155, 2015.

24. Chen X, Wang P, Guo F, Wang X, Wang J, Xu J, Yuan D, Zhang $\mathrm{J}$ and Shao C: Autophagy enhanced the radioresistance of non-small cell lung cancer by regulating ROS level under hypoxia condition. Int J Radiat Biol 93: 764-770, 2017.

25. Saitoh JI, Shirai K, Abe T, Kubo N, Ebara T, Ohno T, Minato K, Saito R, Yamada M and Nakano T; Working Group of The Lung Tumor: A phase I study of hypofractionated Carbon-ion radiotherapy for stage III Non-small cell lung cancer. Anticancer Res 38: 885-891, 2018.

26. Song Y, Zuo Y, Qian XL, Chen ZP, Wang SK, Song L and Peng LP: Inhibition of MicroRNA-21-5p promotes the radiation sensitivity of non-small cell lung cancer through HMSH2. Cell Physiol Biochem 43: 1258-1272, 2017.

27. Carmichael J, Degraff WG, Gamson J, Russo D, Gazdar AF, Levitt ML, Minna JD and Mitchell JB: Radiation sensitivity of human lung cancer cell lines. Eur J Cancer Clin Oncol 25: 527-534, 1989.

28. Guttmann DM, Hart L, Du K, Seletsky A and Koumenis C: Inhibition of Hsp27 radiosensitizes head-and-neck cancer by modulating deoxyribonucleic acid repair. Int J Radiat Oncol Biol Phys 87: 168-175, 2013.

29. Kimura K, Bowen C, Spiegel S and Gelmann EP: Tumor necrosis factor-alpha sensitizes prostate cancer cells to gamma-irradiationinduced apoptosis. Cancer Res 59: 1606-1614, 1999.

30. Ly JD, Grubb DR and Lawen A: The mitochondrial membrane potential (deltapsi(m)) in apoptosis; An update. Apoptosis 8: $115-128,2003$.

31. Dittmann KH, Rothmund MC, Paasch A, Mayer C, Fehrenbacher B, Schaller M, Frauenstein K, Fritsche E, Haarmann-Stemmann T, Braeuning A and Rodemann HP: The nuclear aryl hydocarbon receptor is involved in regulation of DNA repair and cell survival following treatment with ionizing radiation. Toxicol Lett 240: 122-129, 2016.

32. Raviraj J, Bokkasam VK, Kumar VS, Reddy US and Suman V: Radiosensitizers, radioprotectors, and radiation mitigators. Indian J Dent Res 25: 83-90, 2014.

33. Saleh EM: Inhibition of topoisomerase II $\alpha$ sensitizes FaDu cells to ionizing radiation by diminishing DNA repair. Tumour Biol 36: 8985-8992, 2015.

34. Medema RH and Macurek L: Checkpoint control and cancer. Oncogene 31: 2601-2613, 2012.

35. Adeberg S, Bernhardt D, Harrabi SB, Nicolay $\mathrm{NH}$, Hörner-Rieber J, König L, Repka M, Mohr A, Abdollahi A, Weber KJ, et al: Metformin enhanced in vitro radiosensitivity associates with $\mathrm{G} 2 / \mathrm{M}$ cell cycle arrest and elevated Adenosine-5'-monophosphate-activated protein Kinase levels in glioblastoma. Radiol Oncol 51: 431-437, 2017.

36. Lesueur P, Chevalier F, El-Habr EA, Junier MP, Chneiweiss H, Castera L, Müller E, Stefan D and Saintigny Y: Radiosensitization effect of talazoparib, a parp inhibitor, on glioblastoma stem cells exposed to low and high linear energy transfer radiation. Sci Rep 8: 3664, 2018.

37. Luo H, Xi Y, Li W, Li J, Li Y, Dong S, Peng L, Liu Y and Yu W: Cell identity bookmarking through heterogeneous chromatin landscape maintenance during the cell cycle. Hum Mol Genet 26: 4231-4243, 2017.

38. Wang L, Xia Y, Chen T, Zeng Y, Li L, Hou Y, Li W and Liu Z: Sanyang Xuedai enhances the radiosensitivity of human non-small cell lung cancer cells via increasing iNOS/NO production. Biomed Pharmacother 102: 618-625, 2018.

39. Wang Y, Hu L, Zhang X, Zhao H, Xu H, Wei Y, Jiang H, Xie C, Zhou Y and Zhou F: Downregulation of mitochondrial single stranded DNA binding protein (SSBP1) induces mitochondrial dysfunction and increases the radiosensitivity in non-small cell lung cancer cells. J Cancer 8: 1400-1409, 2017.

40. Zhan N, Li B, Xu X, Xu J and Hu S: Inhibition of FASN expression enhances radiosensitivity in human non-small cell lung cancer. Oncol Lett 15: 4578-4584, 2018. 
41. Zhao Y, Jiang W, Li B, Yao Q, Dong J, Cen Y, Pan X, Li J, Zheng J, Pang $X$ and Zhou H: Artesunate enhances radiosensitivity of human non-small cell lung cancer A549 cells via increasing NO production to induce cell cycle arrest at $\mathrm{G} 2 / \mathrm{M}$ phase. Int Immunopharmacol 11: 2039-2046, 2011.

42. Sun X, Zhangyuan G, Shi L, Wang Y, Sun B and Ding Q: Prognostic and clinicopathological significance of cyclin $B$ expression in patients with breast cancer: A meta-analysis. Medicine (Baltimore) 96: e6860, 2017.

43. Ye C, Wang J, Wu P, Li X and Chai Y: Prognostic role of cyclin B1 in solid tumors: A meta-analysis. Oncotarget 8: 2224-2232, 2017.

44. Tashiro E, Tsuchiya A and Imoto M: Functions of cyclin D1 as an oncogene and regulation of cyclin D1 expression. Cancer Sci 98 : 629-635, 2007.

45. Bandopadhyay M, Sarkar N, Datta S, Das D, Pal A, Panigrahi R, Banerjee A, Panda CK, Das C, Chakrabarti S and Chakravarty R: Hepatitis B virus X protein mediated suppression of miRNA-122 expression enhances hepatoblastoma cell proliferation through cyclin G1-p53 axis. Infect Agent Cancer 11: 40, 2016.

46. Min J, Wang X, Tong Y, Li X, Tao D, Hu J, Xie D and Gong J: Expression of cyclins in high-density cultured cells and in vivo tumor cells. Cytometry A 81: 874-882, 2012.

47. Seo HR, Lee DH, Lee HJ, Baek M, Bae S, Soh JW, Lee SJ, Kim J and Lee YS: Cyclin G1 overcomes radiation-induced G2 arrest and increases cell death through transcriptional activation of cyclin B1. Cell Death Differ 13: 1475-1484, 2006.

48. Chang L, Graham PH, Hao J, Ni J, Bucci J, Cozzi PJ, Kearsley JH and Li Y: PI3K/Akt/mTOR pathway inhibitors enhance radiosensitivity in radioresistant prostate cancer cells through inducing apoptosis, reducing autophagy, suppressing NHEJ and HR repair pathways. Cell Death Dis 5: e1437, 2014.

49. Song L, Peng L, Hua S, Li X, Ma L, Jie J, Chen D, Wang Y and Li D: miR-144-5p enhances the radiosensitivity of non-small-cell lung cancer cells via targeting ATF2. Biomed Res Int 2018: 5109497, 2018

50. Zhou HP, Qian LX, Zhang N, Gu JJ, Ding K, Wu J, Lu ZW, Du MY, Zhu HM, Wu JZ, et al: MIIP gene expression is associated with radiosensitivity in human nasopharyngeal carcinoma cells. Oncol Lett 15: 9471-9479, 2018.

51. Shoshan-Barmatz V, Krelin Y and Chen Q: VDAC1 as a player in mitochondria-mediated apoptosis and target for modulating apoptosis. Curr Med Chem 24: 4435-4446, 2017.

52. Sinha K, Das J, Pal PB and Sil PC: Oxidative stress: The mitochondria-dependent and mitochondria-independent pathways of apoptosis. Arch Toxicol 87: 1157-1180, 2013.

53. Wang Y, Xia C, Lv Y, Li C, Mei Q, Li H, Wang H and Li S Crosstalk influence between P38MAPK and autophagy on mitochondria-mediated apoptosis induced by Anti-Fas Antibody/Actinomycin D in human hepatoma Bel-7402 cells Molecules 22: E1705, 2017.
54. Sun Y, Liu WZ, Liu T, Feng X, Yang N and Zhou HF: Signaling pathway of MAPK/ERK in cell proliferation, differentiation, migration, senescence and apoptosis. J Recept Signal Transduct Res 35: 600-604, 2015.

55. Bishayee K, Chakraborty D, Ghosh S, Boujedaini N and Khuda-Bukhsh AR: Lycopodine triggers apoptosis by modulating 5-lipoxygenase, and depolarizing mitochondrial membrane potential in androgen sensitive and refractory prostate cancer cells without modulating p53 activity: Signaling cascade and drug-DNA interaction. Eur J Pharmacol 698: 110-121, 2013.

56. Li D, Dai C, Yang X, Wang F, Yu X, Xiao X and Tang S: Critical role of p21 on olaquindox-induced mitochondrial apoptosis and S-phase arrest involves activation of PI3K/AKT and inhibition of Nrf2/HO-1pathway. Food Chem Toxicol 108: 148-160, 2017.

57. Hassan M, Watari H, AbuAlmaaty A, Ohba Y and Sakuragi N: Apoptosis and molecular targeting therapy in cancer. Biomed Res Int 2014: 150845, 2014.

58. Jiang C, Yuan Y, Hu F, Wang Q, Zhang K, Wang Y, Gu J, Liu X, Bian J and Liu Z: Cadmium induces PC12 cells apoptosis via an extracellular signal-regulated kinase and c-Jun N-terminal kinase-mediated mitochondrial apoptotic pathway. Biol Trace Elem Res 158: 249-258, 2014.

59. Shang HS, Shih YL, Lu TJ, Lee CH, Hsueh SC, Chou YC, Lu HF, Liao NC and Chung JG: Benzyl isothiocyanate (BITC) induces apoptosis of GBM 8401 human brain glioblastoma multiforms cells via activation of caspase-8/Bid and the reactive oxygen species-dependent mitochondrial pathway. Environ Toxicol 31: 1751-1760, 2016

60. Tan M, Rong Y, Su Q and Chen Y: Artesunate induces apoptosis via inhibition of STAT3 in THP-1 cells. Leuk Res 62: 98-103, 2017.

61. Edlich F: BCL-2 proteins and apoptosis: Recent insights and unknowns. Biochem Biophys Res Commun 500: 26-34, 2018.

62. Soriano ME and Scorrano L: The interplay between BCL-2 family proteins and mitochondrial morphology in the regulation of apoptosis. Adv Exp Med Biol 687: 97-114, 2010.

63. Yanagisawa $\mathrm{K}$ and Takahashi T: Protein expression profiling for identification of molecular mechanism in human NSCLC by mass spectrometry (The 20th Lung Cancer Workshop). Jpn J Lung Cancer 46: 231-236, 2006.

64. Ekedahl J, Joseph B, Marchetti P, Fauvel H, Formstecher P, Lewensohn R and Zhivotovsky B: Heat shock protein 72 does not modulate ionizing radiation-induced apoptosis in U1810 non-small cell lung carcinoma cells. Cancer Biol Ther 2: $663-669,2003$

This work is licensed under a Creative Commons Attribution-NonCommercial-NoDerivatives 4.0 International (CC BY-NC-ND 4.0) License. 